\title{
The lobed-lipped species of Haplochromis (Teleostei, Cichlidae) from Lake Edward, two instead of one
}

\author{
Nathan Vranken a,b,*, Maarten Van Steenberge ${ }^{\mathrm{a}, \mathrm{b}, \mathrm{c}}$, Annelies Kayenbergh ${ }^{\mathrm{b}}$, Jos Snoeks ${ }^{\mathrm{a}, \mathrm{b}}$ \\ a Royal Museum for Central Africa, Biology Department, Section Vertebrates, Leuvensesteenweg 13, 3080 Tervuren, Belgium \\ b KU Leuven, Laboratory of Biodiversity and Evolutionary Genomics, Charles Deberiotstraat 32, 3000 Leuven, Belgium \\ ${ }^{\text {c } R o y a l ~ B e l g i a n}$ Institute of Natural Sciences, Operational Directorate Taxonomy and Phylogeny, Vautierstraat 29, 1000 Brussels, Belgium
}

\section{A R T I C L E I N F O}

\section{Article history:}

Received 20 December 2018

13 February 2019

Accepted 8 May 2019

Available online $\mathrm{xxxx}$

Communicated by Bjorn Stelbrink

\section{Keywords:}

Adaptive radiation

Lake Victoria region superflock

Morphometrics

New species

Paralabidochromis

Taxonomy

\begin{abstract}
A B S T R A C T
Thickened lips have evolved several times within the cichlid flocks of the East African Great Lakes. This distinct and easily recognisable phenotype is a model trait to study convergent evolution. Lake Edward (Eastern Africa) contains a unique cichlid assemblage, which has remained largely understudied. Hitherto, only one cichlid species with lobed lips, Haplochromis labiatus, was known from this lake. This species has a blunt snout and rounded and mostly retrognathous jaws. However, we found specimens with lobed lips, but with acute snouts and slender and mostly prognathous jaws. These belong to a species, hitherto unknown to science: $H$. lobatus sp. nov. Both species occur sympatrically. We evaluated the morphological diversity within these species by investigating a total of 112 specimens using traditional and geometric morphometric approaches. Both species are formally (re)described and show a relatively large variation in their trophic morphologies, which complicates identification. Both have a small gape, stout outer teeth that strongly decrease in size laterad, and a lower jaw set anteriorly with procumbently-implanted outer teeth. Haplochromis labiatus differs from H. lobatus sp. nov. by a straight to convex vs. straight to concave head, a slightly shorter and broader lower jaw (27.7-34.3 vs. 31.2-40.7\% HL; 71.4-92.4 vs. 48.5-70.5\% LJL), and lobed lips that are thickened uniformly over their whole lengths vs. medially enlarged. Gut content observations revealed that both species have an insectivorous diet. While both exploit similar food sources, their morphological differences presumably prevent them from entering into direct ecological competition.
\end{abstract}

(c) 2019 International Association for Great Lakes Research. Published by Elsevier B.V. All rights reserved.

\section{Introduction}

Cichlids form one of the most species-rich families of vertebrates with estimates of 2000-3000 species (Salzburger and Meyer, 2004). They are most abundant in freshwater systems in Africa and Central and South America. The species flocks from the East African Great Lakes are known for their large species diversity, which emerged via adaptive radiation and explosive speciation (Fryer and Iles, 1972; Salzburger et al., 2005; Seehausen, 2015; Salzburger, 2018).

Re-occurring traits are well-known within adaptive radiations of fishes (Rundle et al., 2000; Rüber and Adams, 2001; Santos and Salzburger, 2012). One such feature that is especially striking is a strong hypertrophication of the lips. Thickened lips are known to have evolved several times in cichlids (Colombo et al., 2013; Manousaki et al., 2013; Machado-Schiaffino et al., 2014). At least one thick-lipped species is known from each of the radiations of the three largest East African Great Lakes, e.g., Abactochromis labrosus (Trewavas, 1935) from Lake

* Corresponding author at: Royal Museum for Central Africa, Biology Department, Section Vertebrates, Leuvensesteenweg 13, 3080 Tervuren, Belgium.

E-mail address: nathan.vranken@kuleuven.be (N. Vranken).
Malawi, Lobochilotes labiatus (Boulenger, 1898) from Lake Tanganyika, and Haplochromis chilotes (Boulenger, 1911) from Lake Victoria. Thicklipped species have also evolved in other radiations of fishes, such as the large barbs from Lake Tana in Ethiopia with Labeobarbus nedgia Rüppell, 1835 (de Graaf et al., 2008), the species of Garra Hamilton, 1822 from the Sore River in Ethiopia (Golubtsov et al., 2012), the pupfishes from Laguna Chichancanab in Mexico with Cyprinodon labiosus Humphries and Miller, 1981 and C. suavium Strecker, 2005, and the sailfin silversides from the Malili Lakes in Indonesia with Telmatherina sp. 'thicklip' (Pfaender et al., 2016). Furthermore, several distantly-related cichlids from the Neotropics, such as Amphilophus labiatus (Günther, 1864) and Crenicichla tendybaguassu Lucena and Kullander, 1992, also possess thickened lips (Manousaki et al., 2013; Machado-Schiaffino et al., 2014).

Across numerous cichlid species, a continuous gradation in lip hypertrophication can be found (Greenwood, 1980). This makes lip thickness a trait that is difficult to define (Barel et al., 1977). Furthermore, lips are soft tissues that are influenced by preservation. Museum specimens often have shrivelled lips, which renders lip morphology difficult to assess and can lead to misinterpretation of the original structure of the tissue. As a quantifiable definition of lip hypertrophication seems 
unfeasible, we follow a descriptive approach, as suggested by Barel et al. (1977), to define differences in lip thickness (Fig. 1). We define lobed lips as greatly-enlarged lips with spongy structures (Fig. 1d), whereas strongly-thickened lips are greatly-enlarged lips with firm structures (Fig. 1c). In this study, we focus only on specimens that display lobed lips.

Lobed lips presumably form a functional adaptation in cichlids (Losos, 2011; Colombo et al., 2013). It has been suggested that this trait may improve prey detection by increasing the olfactory surface of the lips (Arnegard and Snoeks, 2001), provide protection against mechanical shocks from bumping into rocks during feeding (Manousaki et al., 2013), or increase suction power during feeding by forming a seal against substrates (Kohda et al., 2008; Oliver and Arnegard, 2010). Many species with lobed lips have elongated and slender heads and are insectivorous. This combination of traits seems adaptative to suck insects out of rock crevices or interstices between stones (Kohda et al., 2008; Baumgarten et al., 2015). Yet, the exact adaptive functionality of lobed lips remains uncertain and may be species-specific.

Lobed lips are already present in small-sized specimens (Oliver and Arnegard, 2010). Besides a genetic component, phenotypic plasticity may also play an important role in the development of lobed lips (Machado-Schiaffino et al., 2014). For example, lip size may increase through repeated contact with hard substrates, while it may reduce under unnatural conditions, such as in captivity (Machado-Schiaffino et al., 2014).

The East African Great Lakes harbour unique and diverse fish faunas and provide various resources to local communities (Snoeks et al., 2011). Lake Edward, one of these lakes, is located on the border of the Democratic Republic of the Congo and the Republic of Uganda. Together with Lake George and associated rivers, it forms the Lake Edward system. With the exception of its lacustrine cichlids, this system has a relatively species-poor ichthyofauna that is typical for the East Coast ichthyofaunal province. In comparison to the other rift lakes in this region, the lacustrine part of the Lake Edward system is highly productive and most local communities depend on this system for sustainable livelihoods and economies (Dunn, 1989; Hecky and Degens, 1973). However, the fisheries of the Lake Edward system appear to have collapsed over the last decade, presumably due to the increasing anthropogenic pressures (Balole-Bwami Lubala et al., 2018). Although fisheries are of major importance for local communities, until recently, the ichthyofauna of the Lake Edward system remained largely understudied. A total of 33 haplochromine cichlid species have been described from the system, while it is estimated to be inhabited by $60-100$ species (Greenwood, 1991; Vranken et al., 2019). These species, together with those from Lakes Albert, Kivu, Victoria, and Kyoga and associated river systems, form an adaptive radiation of approximately 700 species that is referred to as the Lake Victoria region superflock (LVRS) (Verheyen et al., 2003; Salzburger et al., 2005). This radiation possibly originated following a hybridisation event between two divergent lineages (Meier et al., 2017), and radiated within the last 100000-200000 years (Verheyen et al., 2003; Bezault et al., 2011). Its species display an extensive diversity in morphology, trophic adaptation, habitat preference, and behaviour (Greenwood, 1980; Witte and van Oijen, 1990; Verheyen et al., 2003; Salzburger et al., 2005).

Based on supposed morphological synapomorphies, Greenwood (1980) proposed a classification of the LVRS in which he reclassified all species within 20 genera. However, this classification was not followed by all subsequent authors as definitions of genera showed considerable overlap and as species could not be placed unambiguously within one of these genera (Hoogerhoud, 1984; Snoeks, 1994; van Oijen, 1996). Furthermore, several genera are now known to be paraphyletic (Meier et al., 2017; Bezault et al., 2011). Hence, until the phylogeny of the LVRS is resolved, we follow Hoogerhoud (1984), Snoeks (1994), van Oijen (1996), de Zeeuw et al. (2010), and Vranken et al. (2019) in classifying all species of the superflock in the genus Haplochromis Hilgendorf, 1888, as prior to Greenwood (1980). However, we do consider Greenwood's (1980) classification to represent a meaningful morphological framework that gives an insight into the morphological diversity within the LVRS. We mention the genera sensu Greenwood (1980) between single quotation marks to indicate that no nomenclatural value is given to them.

Within the genus Haplochromis, three species with lobed lips have been formally described: $H$. chilotes from Lake Victoria, $H$. paucidens Regan, 1921 from Lake Kivu, and H. labiatus Trewavas, 1933 from the Lake Edward system. Greenwood (1980) classified each of these species in 'Paralabidochromis' Greenwood, 1956. Species with a 'Paralabidochromis' morphology can be distinguished from all other species of Haplochromis by the following traits: short oral jaws, deep lower jaws with the ventral sides sloping posteriorly downwards in lateral view, relatively few outer teeth that are stout, straight, and unicuspid, and teeth in the anterior part of the lower jaw with procumbent implantations. In addition to the three lobed-lipped species, the remaining five species within 'Paralabidochromis' sensu Greenwood (1980), all from Lake Victoria, have large to strongly-thickened lips.

Species of Haplochromis display an extensive diversity in morphology. Even within species, morphological variability can be substantial (Snoeks, 1994). In H. chilotes, Greenwood (1959) recognised two sympatric morphotypes: one with strongly lobed lips that were medially enlarged and another with lobed lips that were less-developed and lacked enlarged medial parts. The former morphotype also displayed a more acute snout and more acute dental arcades, and the lower jaw was usually longer than that of the latter morphotype. Seehausen (1996) noted that these two forms could possibly represent two distinct species. A large variability was not observed within $H$. paucidens from Lake Kivu (Snoeks, 1994), whereas the morphological diversity within $H$. labiatus from the Lake Edward system has remained unstudied a

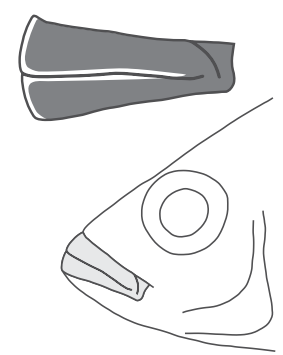

b

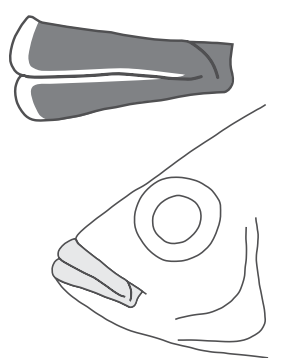

C

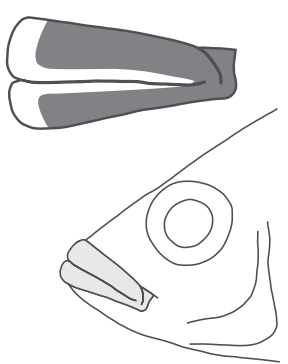

d

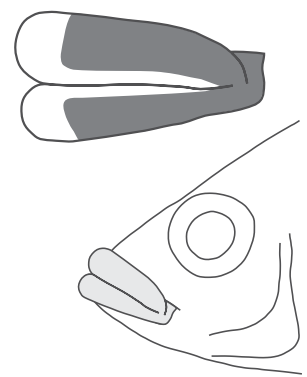

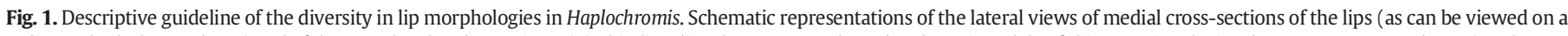

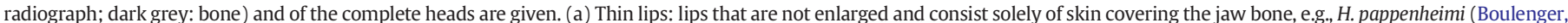

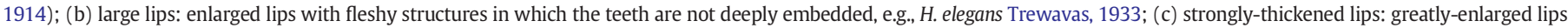

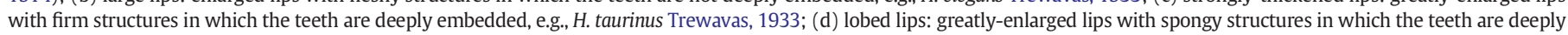
embedded, e.g., H. labiatus. 
(Greenwood, 1973). While collecting specimens from the Lake Edward system, we found lobed-lipped specimens with two distinct morphologies. Some had blunt snouts and rounded and mostly retrognathous jaws, whereas others had acute snouts and slender and mostly prognathous jaws.

The aim of this study is to evaluate the morphological diversity within the lobed-lipped species of Haplochromis from the Lake Edward system. Furthermore, a taxonomical evaluation is presented.

\section{Material and methods}

A total of 112 lobed-lipped specimens from the Lake Edward system with a 'Paralabidochromis' morphology were examined (Fig. 2). These consisted of the holotype of $\mathrm{H}$. labiatus, from the National History Museum, London; 13 specimens from the Royal Institute for Natural Sciences, Brussels; and 98 specimens from the Royal Museum for Central Africa, Tervuren. To refer to collection numbers, the traditional institutional abbreviations BMNH, IRSNB, and MRAC are used, respectively. Small specimens $(<65 \mathrm{~mm} \mathrm{SL})$ were not selected for this study as species-specific characteristics are often missing or difficult to assess in small specimens of Haplochromis (Seehausen, 1996).

One specimen of Haplochromis from Lake George (BMNH 1972.6.2.809) and five specimens of $H$. paucidens from Lake Kivu (MRAC 21483, 22314, 31702, 39848-39849) were investigated as comparative material only. Comparisons to all other species of the LVRS were mainly based on data from Barel et al. (1977), Greenwood (1979, 1980), Seehausen (1996), and Snoeks (1994).

Considerable morphological variation was found within the specimens from the Lake Edward system and two morphological groups were delineated. Specimens of $H$. labiatus had blunt snouts and rounded and mostly retrognathous jaws, whereas those of $H$. sp. 'lobatus' had acute snouts and slender and mostly prognathous jaws. The morphological variation within both groups was further investigated by both traditional and geometric morphometric analyses and by an in-depth investigation of qualitative morphological traits.

\section{Traditional morphometrics}

A total of 49 morphometrics were taken on 70 specimens, consisting of 28 measurements and 21 counts as defined by Vranken et al. (2019): standard length (SL); head length (HL); body depth (BD); predorsal(PrD), preanal- (PrA), prepectoral- (PrP) and prepelvic distance (PrV);

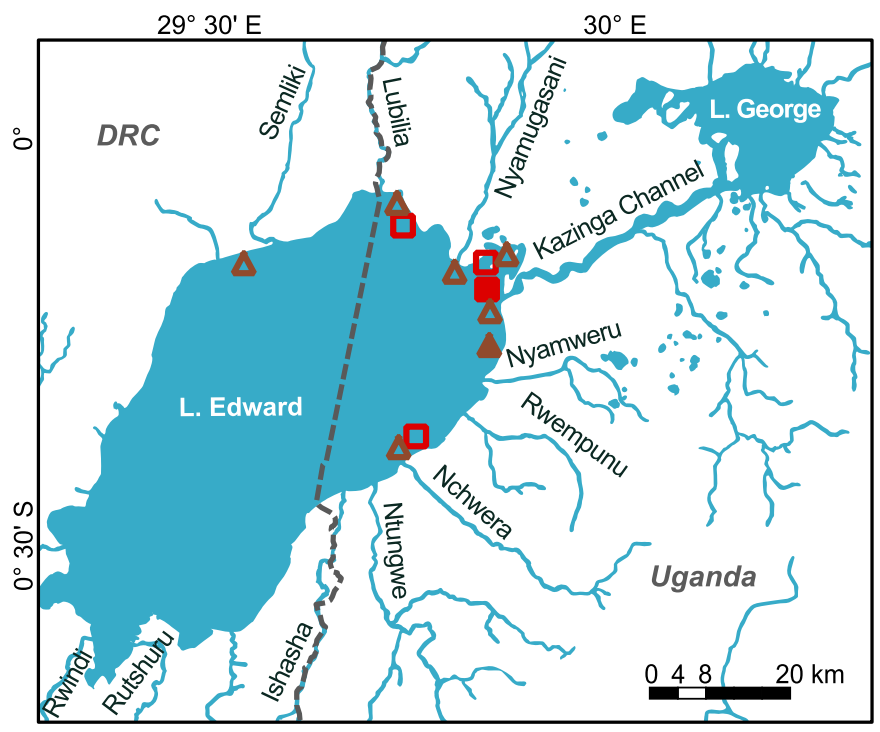

Fig. 2. The Lake Edward system, consisting of Lakes Edward and George connected via the Kazinga Channel. The sampling localities of all examined specimens are indicated: Haplochromis labiatus ( $\triangle$, holotype: $\mathbf{\Delta}$ ), H. lobatus sp. nov. ( $\square$, holotype: $\mathbf{\square})$ pectoral- (PL) and pelvic fin length (VL); dorsal- (DFB) and anal fin base length (AFB); caudal peduncle length (CPL) and depth (CPD); head width (HW); eye diameter (ED); interorbital width (IOW); snout length $(\mathrm{SnL})$; lacrimal depth (LaD); cheek depth (ChD); premaxillary pedicel length (PPL); upper jaw length (UJL); lower jaw length (LJL) and width (LJW); lower pharyngeal length (LPL; $n=5$ ) and width (LPW; $n=5)$; dentigerous area length (DAL; $n=5$ ) and width (DAW; $n=5$ ); gut length (GL; $n=7$ ); upper- (UOT) and lower outer teeth (LOT); upper and lower inner tooth rows (UTR/LTR); dorsal(DFR: DFRs/DFRr), anal- (AFR: AFRs/AFRr), and pectoral fin formulas (PFR), consisting of spine (presented in Roman numerals) and branched-ray counts (presented in decimal numerals); gill raker formula (GR: GRc/1/GRe), consisting of ceratobranchial and epibranchial gill raker counts; abdominal and caudal vertebrae (V: $\mathrm{Va} / \mathrm{Vc})$; longitudinal- (LongL) and lateral line scales (LatL); upper- (D-UUL) and lower transverse line scales (ULL-A); scales between pectoral and pelvic fins (P-V); infraorbital and postorbital cheek scales (ChS: ChSi/ ChSp); and posterior lower pharyngeal teeth (LPTp; $n=5$ ).

All external morphometrics were taken by a single person on the left side of each specimen under a binocular microscope (6.5-50x) using dial callipers $( \pm 0.01 \mathrm{~mm})$. Vertebrae were counted on X-ray scans made with a VisiX X-ray system (Medex Loncin SA) with a DeReO WA detector and a GemX-160 generator. Following the terminology of Barel et al. (1977) and Barel (1983), snout and gape inclinations were measured on X-ray scans in degrees using the parasphenoid bar as a horizontal reference in Image (Rasband, 2018). Gut lengths were measured after removing the digestive tracts under a binocular microscope. Guts were further dissected $(n=10)$, and their contents identified and quantified. Three guts were damaged and could not be measured reliably; nonetheless, their contents were examined.

\section{Geometric morphometrics}

Shape variation in the head morphology of 82 specimens was analysed using a geometric morphometric approach. Digital pictures were taken of the left side of each specimen, or, when crucial structures were damaged, on the mirrored image of the right side. On each picture, 13 fixed landmarks and 11 sliding semi-landmarks were collected. Only points on the head were selected as, for many specimens, bodies were fixated in curved positions. Of the 13 fixed landmarks, 9 were collected following Van Steenberge et al. (2013): anterior tip of the snout just above the lip (Electronic Supplementary Material (ESM) Fig. S1: 1); anterior point of the dorsal fin origin (2); dorsal origin of the operculum (3); ventral point of the suboperculum (4); dorsal end of the preopercular groove (5); anterior (6) and posterior (7) points of the ocular orbit; posterior point of the joint between the lacrimal bone and the orbital rim (8); and ventral end of the fourth lacrimal canal (9). Four additional landmarks were defined as follows: posteriormost point of the operculum at the height of the opercular blotch (10); postero-ventral point of the preoperculum (11); articulation of the lower jaw with the suspensorium (12); and anteroventral point of the lower jaw just posterior of the lower lip (13), at the height of the sixth lateral line foramen sensu Barel et al. (1976). The dorsal outline of the head was captured with 11 sliding semi-landmarks (14-24), equally placed between the tip of the snout (1) and the anteriormost point of the dorsal fin origin (2). Landmarks were collected using tpsDig (Rohlf, 2017a).

\section{Qualitative characteristics}

The following qualitative characteristics were described following the terminology of Barel et al. (1977): dentition on the oral and lower pharyngeal jaws, lateral outline of the neurocranium (based on Xrays), dorsal profile of the head, lateral outline of the snout, maxillary bullation, maxillary posterior extension (in reference to a line perpendicular to the body axis), caudal fin outline, and colouration in live (from pictures) and in alcohol. A distinction was made between terms 
that refer to position, e.g., lateral and dorsal, and terms that refer to directions, e.g., laterad and dorsad, following the terminology proposed by Barel et al. (1976). Specimens were sexed by investigating the genital papillae (Konings, 2014).

\section{Data analysis}

The measurements and counts were analysed separately using principal component analyses (PCA). These were performed on the variance-covariance matrix of the log-transformed measurements and on the correlation matrix of the counts (Zelditch et al., 2004). To allow for comparison, all linear measurements, except for SL, were expressed as percentages of reference measurements. Comparisons of the two groups were performed to reveal possible diagnostic characteristics. These were performed on the proportions of the measurements and on the raw data of the counts by non-parametric Mann-Whitney U (MWU) tests. All tests were performed on a subset of specimens of a similar standard-length class [MWU (SL) $P>0.5$ ], and sequential Bonferroni correction was implemented (Rice, 1989). Measurements with fin tips as reference points (i.e., PL and VL) and angular measurements (i.e., snout and gape inclinations) were excluded from all statistical analyses and tests as these reference structures were often damaged or deformed. Also excluded were measurements and counts taken on a small subset of the specimens (i.e., DAL, DAW, GL, LPL, LPTp, and LPW). All statistical analyses on measurements and counts were performed in Past 3.13 (Hammer et al., 2001).

The landmark data were analysed by PCA and, to compare the two groups, by discriminant function analysis (DFA). All analyses were performed on the variance-covariance matrix of the procrustessuperimposed landmark coordinates (Zelditch et al., 2004). To take sliding semi-landmarks into account, superimposition was performed in tps-Relw (Rohlf, 2017b). All statistical analyses on landmark data were performed using MorphoJ 1.06d (Klingenberg, 2011). Shape variations were visualised as deformed outline drawings (in MorphoJ).

\section{Results}

\section{Traditional morphometrics}

A PCA was performed on the log-transformed measurements of 70 specimens (ESM Table S1). The first principal component (PC 1, 93.3\% of variance) was interpreted as describing size (Zelditch et al., 2004). Lower jaw length, followed by lower jaw width, snout length, and upper jaw length were important contributors to PC 2 (2.3\% of variance). As allometric effects were apparent in PC 2 within both H. labiatus $\left(\mathrm{r}_{\mathrm{PC} 2, \mathrm{sL}}=0.79, \mathrm{P}<0.001\right)$ and $\mathrm{H}$. sp. 'lobatus' $\left(\mathrm{r}_{\mathrm{PC} 1, \mathrm{SL}}=\right.$ $0.62, P=0.001$ ), this axis was plotted against PC 1 , which served as a multivariate proxy of size (Fig. 3a). Haplochromis labiatus had higher values for PC 2 than $H$. sp. 'lobatus'. Both groups overlapped completely in the following axes and no notable patterns could be observed.

In a PCA of the counts, the numbers of tooth rows in the oral jaws were important to PC 1 (10.8\% of variance) (ESM Table S2). For PC 2 (10.0\% of variance) the number of abdominal vertebrae was the main contributor. A plot of PC 2 against PC 1 showed a strong overlap between both groups and no notable patterns could be observed in these (Fig. 3b), or the following axes. However, a quarter of the specimens of $H$. labiatus had higher values for PC 2 than all specimens of $H$. sp. 'lobatus'. Strong overlap between both groups was also observed in the plots of the main PC axes against SL (not shown).

After sequential Bonferonni correction, the MWU tests revealed highly significant differences $(P<0.01)$ between both groups in the proportions of BD, HW, LJL, LJW, IOW, and SnL; while these of VL, CPD, ED, and UJL also differed significantly $(P<0.05)$ (ESM Table S3). Both groups were completely separated by LJW, with 71.4-92.4 (80.3) \% LJL for H. labiatus vs. 48.5-70.5 (62.5) \% LJL for $H$. sp. 'lobatus' In the other nine aforementioned measurements, ranges often overlapped,
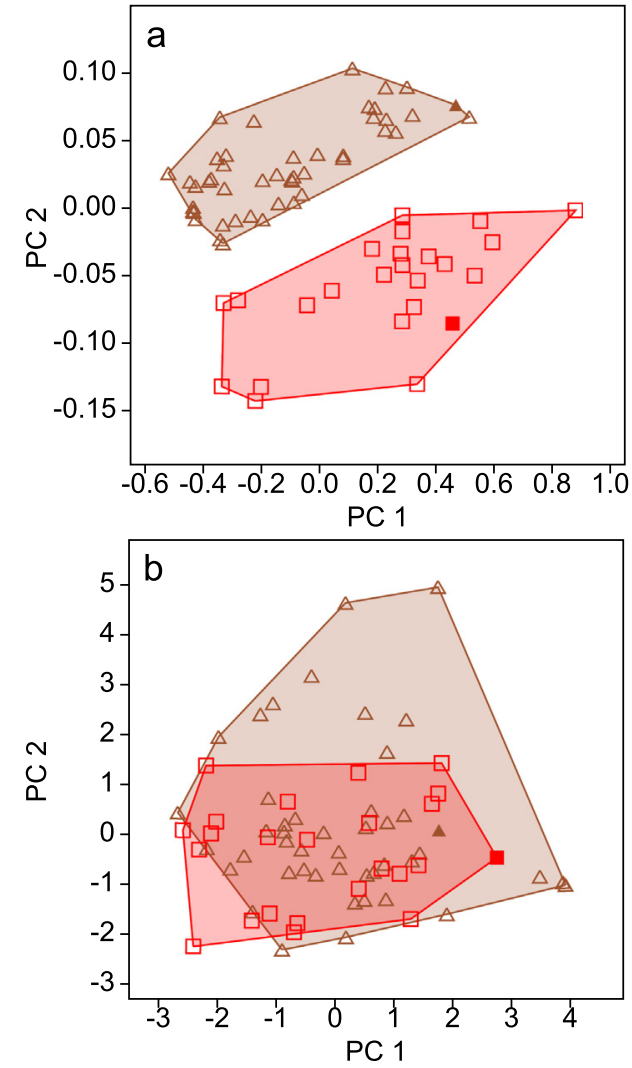

Fig. 3. Plots of $P C 2$ vs. PC 1 of PCAs on (a) the log-transformed measurements and (b) the raw counts from Haplochromis labiatus ( $\Delta$, holotype: $\mathbf{\Delta}$ ) and $H$. lobatus sp. nov. ( $\square$, holotype: $\mathbf{\square})$. For PCA loadings, see Tables S1-2.

presumably due to allometric effects. To allow for better identification, proportions of these measurements were given for three lengthclasses (ESM Table S4).

\section{Geometric morphometrics}

The procrustes-superimposed coordinates of the landmarks of 82 specimens were analysed by PCA (ESM Table S5). Visualisations of the shape changes revealed that an increasing value in PC 1 (26.9\% of variance) corresponded with an expansion of the buccal cavity by an enlargement of the snout and a posterior displacement of the operculum (ESM Fig. S2a). The second PC (18.9\% of variance) was mainly determined by the profile of the head. An increasing value in this axis corresponded with a steeper snout inclination, a decrease in the depth of the dorso-posterior part of the head, an increase in operculum depth, and an increase in eye size (ESM Fig. S2b). Both PC 1 and PC 2 were plotted against SL (ESM Fig. S2). The two groups overlapped largely on both axes, while on PC 2, strong effects of allometric growth were observed within both groups $\left(\mathrm{r}_{\mathrm{PC} 2}\right.$, sL $=-0.70, \mathrm{P}<0.001$ for H. labiatus; $\mathrm{r}_{\mathrm{PC}} 2, \mathrm{sL}=-0.74, \mathrm{P}<0.001$ for $H$. sp. 'lobatus'). Similar to PC 2, the profile of the head mainly determined PC 3 (15.6\% of variance). Furthermore, an increasing value in PC 3 corresponded to a shallower gape inclination, a less anteriorly extending lower jaw, slight increases in the size and posterior displacement of the eye, and a less deep operculum (Fig. 4a). A plot of PC 3 against SL revealed some overlap between small specimens $(<88 \mathrm{~mm} \mathrm{SL})$, while large specimens $(>88 \mathrm{~mm} \mathrm{SL})$ were completely separated, with $H$. labiatus having larger values than H. sp. 'lobatus'.

A comparison of the two groups by a DFA of the procrustes superimposed coordinates of the landmarks showed a clear separation between both groups (Fig. 4b, ESM Table S6). The characteristics that best explained PC 3 were also important to the discriminant function 

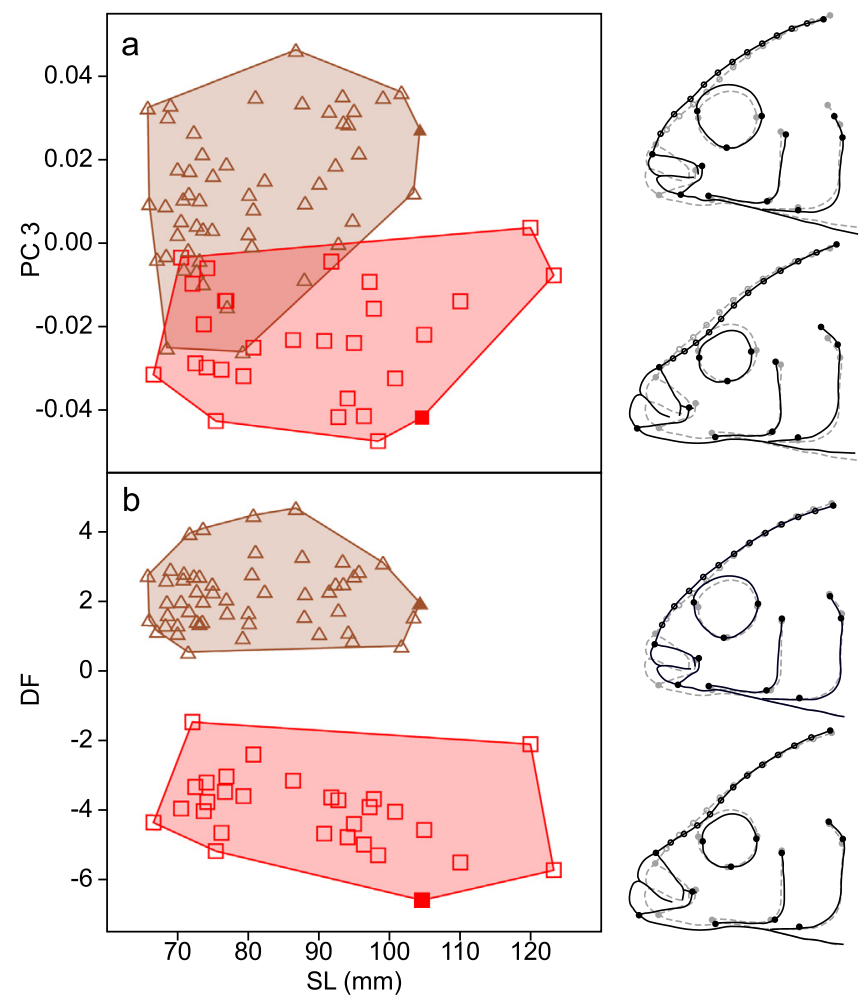

Fig. 4. Plots of (a) PC 3 and (b) DF vs. SL, respectively of a PCA and a DFA on the procrustessuperimposed coordinates of the landmarks from Haplochromis labiatus ( $\triangle$, holotype: $\mathbf{\Delta}$ ) and $H$. lobatus sp. nov. ( $\square$, holotype: $\square)$. For each axis, graphs of shape variations that represent a change of 0.1 units (PCA) or 10 units (DFA) in the positive and negative directions of the corresponding axis are shown. Dotted grey line: consensus; full black line: corresponding shape variation; dot: fixed landmark; circle: sliding semi-landmark. For PCA and DFA loadings, see Tables S5-6.

(DF) (Fig. 4). In both, positive values corresponded to a more convex profile of the head, a less anteriorly extending lower jaw, and a larger eye. Furthermore, an increasing value in the DF corresponded with a slightly more anteriad position of the eye.

\section{Qualitative characteristics}

Specimens of $H$. labiatus had blunt snouts, rounded and mostly retrognathous jaws (Fig. 5a), whereas those of $H$. sp. 'lobatus' had acute snouts, slender and mostly prognathous jaws (Fig. 5b). Further investigation of qualitative characteristics revealed that both groups had few and strong outer oral teeth that were anteriorly inclined in the anterior part of the lower jaw. However, differences were found in the form and setting of these teeth. In H. labiatus, they were regularly set and had short and blunt crowns, while in $H$. sp. 'lobatus', they were mostly irregularly set and had relatively long and bluntly pointed crowns. Although all specimens of both groups displayed lobed lips, in $H$. sp. 'lobatus', the medial parts were mostly enlarged, while the lips were thickened uniformly over their whole lengths in H. labiatus. In addition, subtle differences in dominant male colouration were observed (see Systematic account).

A redescription of $H$. labiatus and a formal description of $H$. lobatus sp. nov. follow below. For each species, the proportions of the measurements and raw counts are given in Table 1 .

\section{Systematic account}

Haplochromis labiatus Trewavas, 1933

(Figs. 5a, 6, ESM S3, ESM S4; Tables 1, ESM S4)

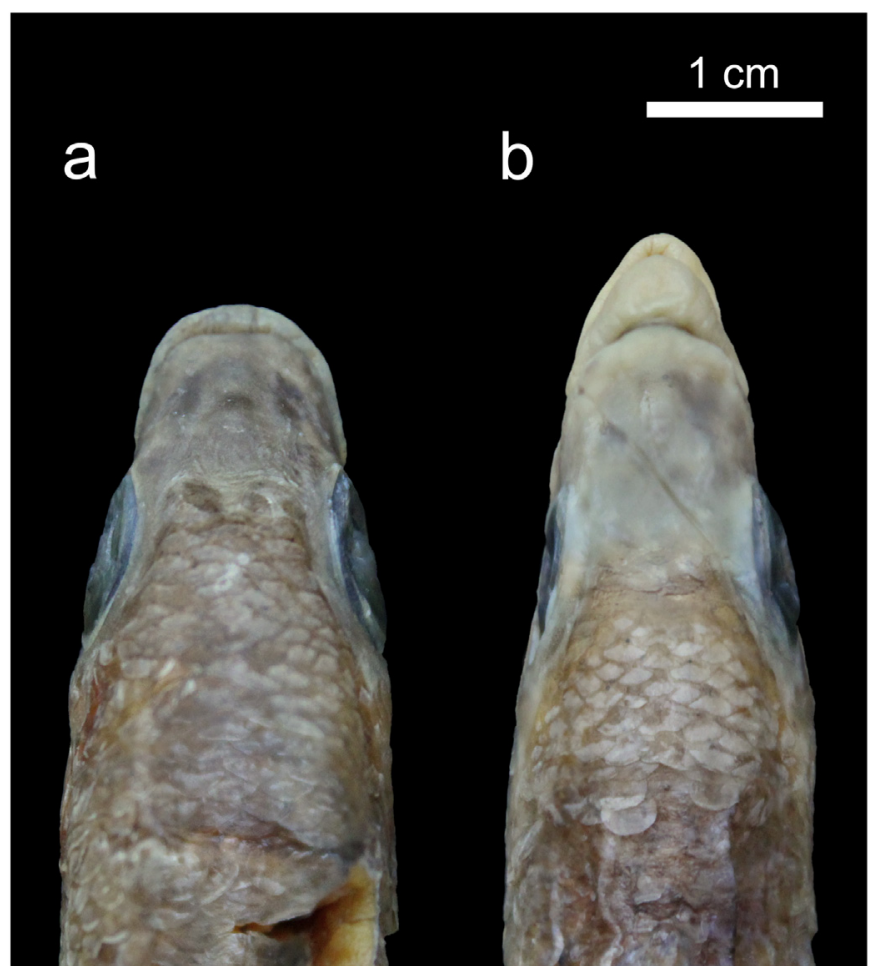

Fig. 5. Dorsal views of the heads of (a) H. labiatus (MRAC 2017.06.P.0201) and (b) H. lobatus sp. nov. (MRAC 2017.06.P.0068). While H. labiatus resembles H. lobatus sp. nov. in snout length, it differs in having a rounded vs. slender snout, lobed lips that are thickened uniformly over their whole lengths vs. medially enlarged, and a mostly retrognathous lower jaw that is not visible dorsally vs. a prognathous lower jaw that is visible dorsally.

\section{Synonyms}

Paralabidochromis labiatus: Greenwood, 1980

Holotype

BMNH 1933.2.23.403; Lake Edward, 8 km south of mouth Kazinga Channel $0^{\circ} 17^{\prime} 05^{\prime \prime} \mathrm{S} 29^{\circ} 52^{\prime} 45^{\prime \prime} \mathrm{E}$; 09/06/1931 [O $104.3 \mathrm{~mm} \mathrm{SL}$ ].

Additional material examined [examined by traditional- $(T)$ and/or geometric morphometrics $(G)]$

IRSNB 12896; Kiavinionge, pier, Lake Edward 009'19' $29^{\circ} 33^{\prime} 20^{\prime \prime} \mathrm{E}$; 1/06/1953 [ $n=13$ (T:13, G:11); 65.9-80.6 mm SL]. MRAC 2016.35. P.0073; 'Coral Reef', mouth of Nyamugasani river, Lake Edward $0^{\circ} 10^{\prime}$ 08.4"S 2949'37.2"E; 21/10/2016 [ $n=1$ (T:1, G:0); 72.6 mm SL]. MRAC 2016.35.P.0074-75; Mouth of Kazinga Channel, Lake Edward $0^{\circ} 12^{\prime} 32.4^{\prime \prime} \mathrm{S} 29^{\circ} 53^{\prime} 06.0^{\prime \prime} \mathrm{E} ; 24 / 10 / 2016$ [ $n=2$ (T:2, G:1); 77.0, $86.3 \mathrm{~mm} \mathrm{SL}$. MRAC 2016.35.P.0076-78, 80-86, 91-99, 102-107; Rwenshama, rocky shore, Lake Edward $0^{\circ} 24^{\prime} 05.7^{\prime \prime} \mathrm{S} 29^{\circ} 46^{\prime} 35.1^{\prime \prime} \mathrm{E} ; 08 /$ 11/2016 [ $n=25$ (T:24, G:11); 68.6-98.1 mm SL]. MRAC 2016.35. P.0110; Rwenshama, rocky shore, Lake Edward 0²4'05.7"S 2946' 35.1"E; 09/11/2016 [ $n=1$ (T:1, G:0); 80.7 mm SL]. MRAC 2017.06. P.0159; Mouth of Kazinga Channel, hard substrate, Lake Edward $0^{\circ} 12^{\prime}$ $14.4^{\prime \prime}$ S 2952'37.2"E; 24/03/2017 [ $n=1$ (T:1, G:1); 103.0 mm SL]. MRAC 2017.06.P.0163; Rwenshama, rocky shore, Lake Edward $0^{\circ} 24^{\prime}$ 05.7"S 2946'35.1"E 26/03/2017 [ $n=1$ (T:0, G:1); 70.6 mm SL]. MRAC 2017.06.P.0171-177, 190-193; Kayanja offshore, Lake Edward $0^{\circ} 05^{\prime} 34.8^{\prime \prime} \mathrm{S} 29^{\circ} 45^{\prime} 28.8^{\prime \prime} \mathrm{E} 30 / 03 / 2017$ [ $n=11$ (T:0, G:11); 72.8-99.1 mm SL]. MRAC 2018.08.P.0187; Islands near Katwe, Lake Edward $0^{\circ} 10^{\prime} 04.9^{\prime \prime} \mathrm{S} 29^{\circ} 52^{\prime} 27.4^{\prime \prime} \mathrm{E}$ 19/01/2018 [ $n=1$ (T:0, G:1); $93.4 \mathrm{~mm}$ SL]. MRAC 2017.06.P.0201-203, 216-219; Kayanja offshore, Lake Edward $0^{\circ} 05^{\prime} 34.8^{\prime \prime S} 29^{\circ} 45^{\prime} 28.8^{\prime \prime} \mathrm{E} 31 / 03 / 2017$ [ $n=6$ (T:3, G:5); 73.2-95.0 mm SL]. MRAC 2018.08.P.0194-201, 218; Kayanja, offshore, 
Table 1

Measurements and counts from Haplochromis labiatus and H. lobatus sp. nov., both endemic to the Lake Edward system. Acronyms are explained in Methods, Measurements taken from a subsample of specimens are indicated by asterisks $\left(^{*}\right)$.

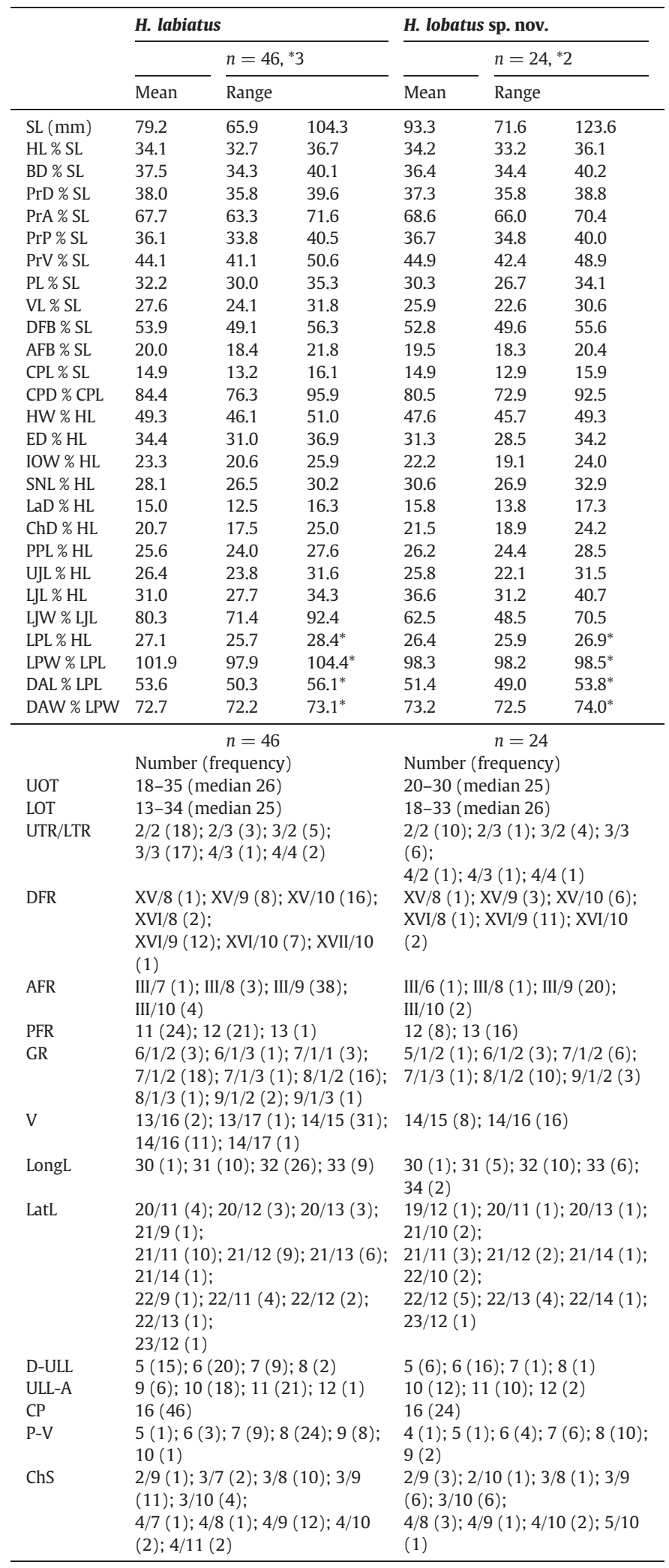

Lake Edward 005'31.2"S 2945'30.3"E 20/01/2018 [ $n=9$ (T:0, G:9); 67.2-88.1 mm SL]. MRAC 2018.08.P.0220; Bought at Rwenshama landing site, Lake Edward 0²4'16.0"S 2946'24.8"E 23/01/2018 [ $n=1$ (T:0, $\mathrm{G}: 1) ; 101.7 \mathrm{~mm} \mathrm{SL}]$.

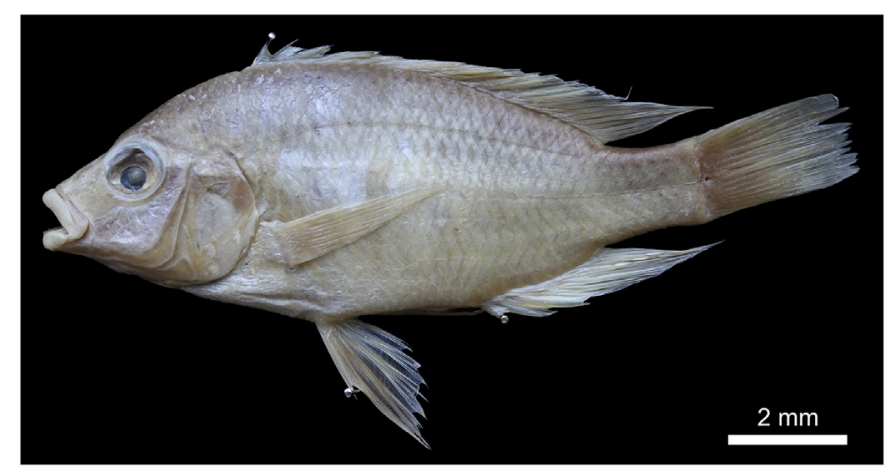

Fig. 6. Haplochromis labiatus, holotype, $ๆ 104.3$ mm SL. BMNH 1933.2.23.403.

\section{Etymology}

Origin of specific name not explained in original description, adjective derived from the Latin noun 'labium', lip, referring to the lobed lips of the species.

\section{Description}

Body deep; head straight to moderately convex; snout blunt and steep with an inclination of $40-55^{\circ}$. Jaws iso- to retrognathous; gape small and with an inclination of $10-30^{\circ}$; maxilla extends to between nostril and anterior margin of orbit. Lower jaw stout, short, broad, anteriorly deep, posteriorly very deep, and with a rounded outline anteroventrally in lateral view. Upper jaw stout, short, with dentigerous arm of premaxilla curving gently downwards, and with a long premaxillary pedicel in comparison to upper jaw length [78.7-111.4 (97.2) \% UJL]. Lips lobed uniformly over whole lengths and oral mucosa very strongly thickened. Neurocranium with relatively deep preorbital region, and with deep and pyramidical supraoccipital crest (ESM Fig. S3a). Chest scales small; transition to flank scales gradual.

Outer oral teeth large, very stout, relatively few, and deeply embedded in oral mucosa. Necks straight, long, and cylindrical; crowns slightly recurved, very short, and stout. Major cusps blunt and equilateral to subequilateral; minor cusps, if present, short and blunt; cusp gaps narrow. Dental arcades rounded and relatively slender. Outer teeth regularly and closely set with $0-1$ outer tooth width between adjacent teeth. Lateral and posterior outer teeth with straight implantations and almost completely embedded in oral mucosa. Three to five anteriormost outer teeth in lower jaw procumbently implanted on anterior margin of lower jaw ( $40-60^{\circ}$ to vertical), and in both jaws large and unicuspid in large specimens $(>80 \mathrm{~mm} \mathrm{SL})$, while in small specimens ( $<70 \mathrm{~mm} \mathrm{SL}$ ) uni-, weakly bi-, to rarely bicuspid and slightly symphyseally sensu Witte and Witte-Maas (1981) inclined. Outer teeth strongly decrease in size laterad (abruptly in lower jaw). Lateral outer teeth uni- to weakly bicuspid; in small specimens ( $<80 \mathrm{~mm} \mathrm{SL})$ mostly bicuspid. In large specimens ( $>90 \mathrm{~mm} \mathrm{SL}$ ), 2-3 posteriormost outer teeth in upper jaw enlarged and more stout than adjacent teeth. Tooth bands crescent-shaped and slender with 2-4 rows of inner teeth anteriorly that narrow laterad, until only outer rows remain. Inner teeth uni- to weakly tricuspid, bluntly pointed, and widely and irregularly set on $1 / 2-1$ outer tooth width from outer rows. Inner teeth anteriorly in first row large and stout, while decreasing in size orally. Anteriormost inner and outer teeth often abraded.

Lower pharyngeal bone triangular and equally deep over entire length (ESM Fig. S4). Pharyngeal teeth relatively slender and bluntly pointed with cylindrical to slightly constricted necks, bluntly pointed major cusps, concave major cusp gaps, and blunt minor cusps. Teeth in posteriormost transverse row more stout, blunt, and weakly bicuspid; teeth in two median longitudinal rows stout.

Caudal fin emarginate. Dorsal and anal fins reach level between one scale anterior to and one scale posterior to caudal fin base. Pectoral fins 
reach level between genital opening and first anal fin spine; pelvic fins between genital opening and third anal fin spine.

Ceratobranchial gill rakers in outer row of first gill arch unifid and short, posteriormost rakers rarely bifid in large specimens $(>80 \mathrm{~mm}$ $\mathrm{SL})$. Epibranchial gill rakers short and relatively slender.

\section{Colouration in life}

Dominant males: body, cheeks, and operculum beige to blue with yellow sheen; dorsum with greenish sheen; chest dusky; flanks with 5-7 faint, dusky, and blue vertical stripes (ESM Fig. S3b). Snout and lower jaw turquoise; lips beige to dusky; nostril, interorbital, supraorbital, and vertical preopercular stripes and nape band faint and illdefined. Pectoral fins hyaline; pelvic fins black. Dorsal fin dusky and anteriorly with black lappets, posteriorly orange-red lappets, and maculated orange-red between branched rays. Anal fin white, base dusky, extensions bright yellow, and with 3-5 small orange egg spots (i.e., size of distance between rays) with black borders. Caudal fin bright orange to orange-red and with dusky base.

Females and juveniles: body beige with yellow sheen; dorsum with blue-green sheen; cheeks, operculum, chest, and belly white; flanks with 5-7 very faint dusky vertical stripes (ESM Fig. S3c). Pectoral fins hyaline, pelvic fins white. Dorsal fin dusky and with black lappets; caudal fin dusky with yellow to orange extensions and dorsal part faintly maculated. Anal fin white and with dusky-yellow base and with yellow extensions and 2-4 small orange spots that resemble egg spots.

\section{Colouration in alcohol}

Dorsum brown, ventral part of body silver-beige; dominant males uniformly brown (Fig. 6). Flanks with 5-7 faint vertical stripes. Pectoral fins hyaline; pelvic fins hyaline in females and juveniles, dark in dominant males. Dorsal, anal, and caudal fins dusky in females and juveniles; caudal fin with hyaline extensions and anal fin with 3-5 faint egg spots in dominant males. Nostril, interorbital, preopercular, and lachrymal stripes and a nape band faint and ill-defined.

\section{Ecology and distribution}

Endemic to the Lake Edward system, only known from Lake Edward. Gut short (116-165\% SL, $n=4$ ), diet insectivorous. We examined the gut contents of five specimens. Two were filled with larvae of Chironomidae, Ephemeroptera, and Trichoptera, some Ostracoda, and remains of Diptera larvae and Heteroptera. Two were empty, one was almost empty except for several Chironomidae larvae. A small amount of plant tissue was found in one of the filled guts.

\section{Systematic comment}

Greenwood (1973) based his redescription of $H$. labiatus on a single specimen from Lake George (BMNH 1972.6.2.809). He found small differences between this specimen and the holotype that he attributed to the smaller size of the specimen ( 85.5 vs. $104.3 \mathrm{~mm} \mathrm{SL}$ ). We examined this specimen from Lake George and found some of these and some other differences between this specimen and the H. labiatus specimens studied here. The specimen from Lake George differs by a less stout, less deep, and more slender lower jaw (67.5 vs. 71.4-92.4\% LJW), straight vs. curved dentigerous arms of the premaxilla, clearly lessdeveloped lips, and smaller inner and outer teeth. Its outer teeth are more slender, more acute, more numerous (UOT 39 vs. 18-35), and the major cusps with vs. without small flanges. Its outer teeth in the anterior part of the lower jaw are less procumbently implanted (10 vs. $40-60^{\circ}$ to perpendicular to dentigerous area) and bicuspid vs. unicuspid in similar-sized specimens of $H$. labiatus. Its head is concave vs. straight to convex, its eye smaller ( 29.9 vs. $31.0-36.9 \% \mathrm{HL}$ ), its cheek deeper (26.1 vs. 17.5-25.0\% HL), and its lower pharyngeal bone more slender (89.0 vs. 97.9-104.4\% LPL). As this specimen deviates from H. labiatus it cannot be considered conspecific with this species. Its morphology suggests that it belongs to a more generalistic species sensu Barel et al. (1976).

\section{Differential diagnosis}

Haplochromis labiatus differs from all known species of Haplochromis from the Lake Edward system by a combination of a blunt snout, retroto isognathous jaws, deep lower jaw with blunt teeth, and lobed lips. It can be confused with $H$. lobatus sp. nov. as both have lobed lips, a small gape, a curved upper jaw with a relatively long premaxillary pedicel [78.7-111.4 (97.2) \% UJL], stout and unicuspid outer teeth that strongly decrease in size laterad, and a lower jaw set anteriorly with procumbently implanted outer teeth on the anterior margin of the lower jaw $\left(40-60^{\circ}\right.$ to vertical). It differs from this species by a straight to convex vs. straight to concave head, and a blunt and more broad vs. elongated and slender snout (Tables 1, ESM S4). Differs further in its trophic morphology: lower jaw slightly shorter [27.7-34.3 (31.0) vs. 31.2-40.7 (36.6) \% HL] and more broad [71.4-92.4 (80.3) vs. 48.5-70.5 (62.7) \% LJL], jaws iso- to retrognathous vs. iso- to strongly prognathous, and anteriormost outer teeth in lower jaw more closely set (0-1 vs. 1-2 outer tooth widths between adjacent teeth) and with shorter major cusps.

Haplochromis labiatus resembles $H$. paucidens from Lake Kivu by a blunt head, lobed lips, and insectivorous diet. It differs by a shallower lacrimal and a larger eye [LaD 36.3-50.9 (43.6) vs. 51.7-62.4 (55.5) \% ED] and a slightly broader head [46.1-51.0 (49.3) vs. 43.9-47.1 (46.0) $\% \mathrm{HL}]$. It further differs by mainly unicuspid vs. bicuspid outer teeth with stouter major cusps and mainly unicuspid vs. tricuspid inner teeth. No notable difference in dominant male colouration has been observed but a piebald colouration is seemingly absent in $\mathrm{H}$. labiatus, while it is frequently observed in $H$. paucidens (30-36\% of specimens; Snoeks, 1994). Haplochromis labiatus resembles superficially $H$. chilotes from Lake Victoria by lobed lips but differs by a blunt vs. acute snout and a larger eye [31.0-36.9 (34.4) vs. 21.8-28.6 (25.4) \% HL]

\section{Haplochromis lobatus sp. nov.}

(Figs. 5b, 7, S5, \& S6; Tables 1 \& S4)

Holotype

MRAC 2016.35.P.0063; Mouth of Kazinga Channel, Lake Edward $0^{\circ} 12^{\prime} 32.4^{\prime \prime} \mathrm{S} 29^{\circ} 53^{\prime} 06.0^{\prime \prime} \mathrm{E} ; 24 / 10 / 2016$ [우 $104.6 \mathrm{~mm} \mathrm{SL}$ ].

Paratypes [all examined by traditional morphometrics; some also by geometric morphometrics $(G)]$

IRBNS 890-891; Kayanja offshore, Lake Edward 005'34.8'S $29^{\circ} 45^{\prime}$ 28.8"E; 31/03/2017 [ $n=2$ (G:1); 75.3, 97.8 mm SL]. IRBNS 892-893; Rwenshama, rocky shore, Lake Edward $0^{\circ} 24^{\prime} 05.7^{\prime \prime} \mathrm{S} 29^{\circ} 46^{\prime} 35.1^{\prime \prime} \mathrm{E} ; 26 /$ 03/2017 [ $n=2$ (G:1); 71.6, $72.3 \mathrm{~mm} \mathrm{SL}$ ]. IRBNS 894; Islands near Katwe, Lake Edward $0^{\circ} 10^{\prime} 04.9^{\prime \prime} \mathrm{S} 29^{\circ} 52^{\prime} 27.4^{\prime \prime} \mathrm{E} 18 / 01 / 2018$ [ $n=1$ (G:1); 72.4 mm SL]. MRAC 2016.35.P.0064-71; Mouth of Kazinga Channel, Lake Edward $0^{\circ} 12^{\prime} 32.4^{\prime \prime} \mathrm{S} 29^{\circ} 53^{\prime} 06.0^{\prime \prime} \mathrm{E} ; 24 / 10 / 2016$ [ $n=8$ (G:6); 90.8-110.0 mm SL]. MRAC 2016.35.P.0072; Rwenshama, rocky shore, Lake Edward $0^{\circ} 24^{\prime} 05.7^{\prime \prime} \mathrm{S} 29^{\circ} 46^{\prime} 35.1^{\prime \prime} \mathrm{E}$; 08/11/2016 [ $n=1$ (G:1); $94.2 \mathrm{~mm}$ SL]. MRAC 2017.06.P.0127-132; Kayanja offshore, Lake Edward $0^{\circ} 05^{\prime} 34.8^{\prime \prime} \mathrm{S} \quad 29^{\circ} 45^{\prime} 28.8^{\prime \prime} \mathrm{E} ; 31 / 03 / 2017 \quad[n=6$ (G:3); 75.2-104.2 mm SL]. MRAC 2017.06.P.0154; Kayanja offshore, Lake

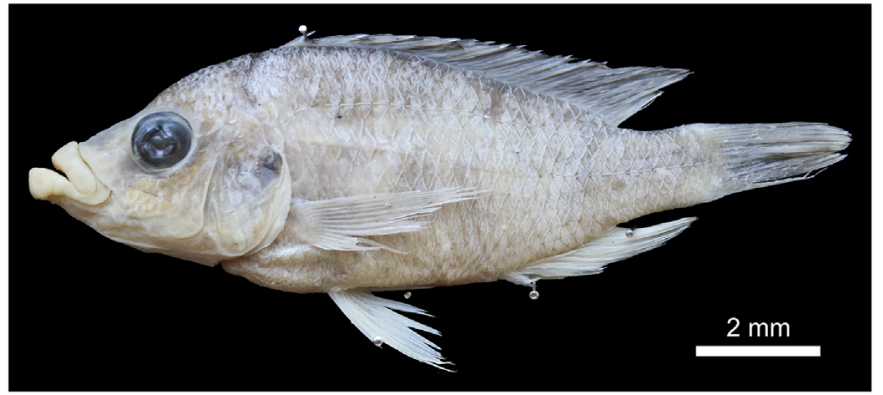

Fig. 7. Haplochromis lobatus sp. nov., holotype, ᄋ 104.6 mm SL. MRAC 2017.06.P.0063. 
Edward 005'34.8'S 2945'28.8"E; 30/03/2017 [ $n=1$ (G:1); 85.1 mm SL]. MRAC 2018.08.P.0183-184; Bought at Rwenshama landing site, Lake Edward $0^{\circ} 24^{\prime} 16.0^{\prime \prime} \mathrm{S} 29^{\circ} 46^{\prime} 24.8^{\prime \prime} \mathrm{E} ; 24 / 01 / 2018$ [ $n=2$ (G:2); 104.0, $123.6 \mathrm{~mm} \mathrm{SL}]$.

Additional specimens examined (no paratypes; all examined by geometric morphometrics only).

MRAC 2017.06.P.0119-121, 149; Rwenshama, rocky shore, Lake Edward $0^{\circ} 24^{\prime} 05.7^{\prime \prime S} 29^{\circ} 46^{\prime} 35.1^{\prime \prime}$ E. 26/03/2017 [ $n=4$; 66.7-91.8 mm SL]. MRAC 2017.06.P.0133-134; Kayanja offshore, Lake Edward 005'34.8"S 2945'28.8'E; 31/03/2017 [ $n=2 ; 75.5,79.4$ mm SL]. MRAC 2017.06. P.0151-152; Kayanja offshore, Lake Edward 005'34.8"S 2945'28.8”E; 30/03/2017 [ $\mathrm{n}=2 ; 76.3,97.2 \mathrm{~mm}$ SL]. MRAC 2018.08.P.0174, 176, 178-180; Islands near Katwe, Lake Edward 0¹0'04.9"S 2952'27.4"E; $18 / 01 / 2018$ [ $n=5 ; 70.6-80.8 \mathrm{~mm}$ SL]. MRAC 2018.08.P.0182; Islands near Katwe, Lake Edward 0¹0'04.9"S 2952'27.4"E; 19/01/2018 [ $n=$ 1; $90.8 \mathrm{~mm} \mathrm{SL]}$. MRAC 2018.08.P.0185; Bought at Rwenshama landing site, Lake Edward $0^{\circ} 24^{\prime} 16.0^{\prime \prime} \mathrm{S} 29^{\circ} 46^{\prime} 24.8^{\prime \prime} \mathrm{E}$; 24/01/2018 [ $n=1$; $119.9 \mathrm{~mm} \mathrm{SL}]$.

\section{Etymology}

Specific name from Latin 'lobatus', lobed. Refers to its lobed lips that are often medially enlarged.

\section{Description}

Body deep; head concave to straight; snout elongated, very slender, acute, and with an inclination of $30-45^{\circ}$. Jaws iso- to strongly prognathous (i.e., inner teeth in lower jaw in some specimens visible in dorsal view when mouth closed); gape small and with an inclination of $20-40^{\circ}$; maxilla extends to between nostril and anterior margin of orbit. Lower jaw very slender, stout, anteriorly deep, posteriorly very deep, and with a rounded outline anteroventrally in lateral view. Upper jaw stout, short, with dentigerous arm of premaxilla curving gently downwards, and with a long premaxillary pedicel in comparison to upper jaw length [82.4-116.3 (102.1) \% UJL]. Lips lobed with medial parts mostly enlarged and oral mucosa very strongly thickened. Neurocranium with relatively deep preorbital region, and with a deep and pyramidical supraoccipital crest (ESM Fig. S5a). Chest scales small; transition to flank scales gradual.

Outer oral teeth large, stout, relatively few, and deeply embedded in oral mucosa. Necks straight, long, and cylindrical; crowns straight to slightly recurved, short, and stout. Major cusps bluntly pointed and equilateral to subequilateral; minor cusps, if present, short and blunt; cusp gaps narrow. Dental arcades long, acute, and very slender. Lateral and posterior outer teeth regularly and closely set with $1 / 2-1$ outer tooth width between adjacent teeth; anterior outer teeth widely and irregularly set on 1-2 outer tooth widths. Lateral and posterior teeth with straight implantations and almost completely embedded in oral mucosa. Four to eight anteriormost outer teeth in lower jaw large, procumbently implanted on anterior margin of lower jaw $\left(40-70^{\circ}\right.$ to vertical), and in all specimens unicuspid. Outer teeth strongly decrease in size laterad (abruptly in lower jaw). Lateral outer teeth uni- to weakly bicuspid; in small specimens ( $<80 \mathrm{~mm} \mathrm{SL}$ ) often bicuspid. In large specimens ( $>95 \mathrm{~mm} \mathrm{SL}$ ), 2-3 posteriormost outer teeth in upper jaw enlarged and more stout than adjacent teeth. Tooth bands crescentshaped and relatively slender with 2-4 rows of inner teeth anteriorly that narrow laterad, until only outer rows remain. Inner teeth uni- to weakly tricuspid, bluntly pointed, and widely and irregularly set on $1 / 2-1$ outer tooth width from outer rows. Inner teeth anteriorly in first row large and stout, while decreasing in size posteriad. No teeth abraded.

Lower pharyngeal bone triangular and equally deep over entire length (ESM Fig. S6). Pharyngeal teeth slender with cylindrical to slightly constricted necks, bluntly pointed major cusps, concave major cusp gaps, and blunt minor cusps. Teeth in posteriormost transverse row more stout, blunt, and weakly bicuspid; teeth in two median longitudinal rows stout.

Caudal fin emarginate. Dorsal and anal fins reach level between one scale anterior and one scale posterior to caudal fin base. Pectoral fins reach level between genital opening and first anal fin spine; pelvic fins between genital opening and third anal fin spine.

All ceratobranchial gill rakers in outer row of first gill arch unifid and short, posteriormost rakers rarely bi- or trifid in large specimens (>100 mm SL). Epibranchial gill rakers short and slender.

\section{Colouration in life}

Dominant males: Body, cheeks, and operculum green to cream yellow; dorsum green; chest dusky; flanks of some specimens with 4-6 very faint and dusky vertical stripes (ESM Fig. S5b-c). Snout and lower jaw turquoise; lips beige to dusky; nostril, interorbital, supraorbital, and vertical preopercular stripes and nape band faint and ill-defined. Pectoral fins hyaline to dusky; pelvic fins black. Dorsal and anal fins dusky to black, dorsal fin anteriorly with black lappets, posteriorly with orange-red lappets, and maculated orange-red between branched rays. Anal fin dusky with yellow to orange extensions and 4-7 small orange egg spots (i.e., size of distance between rays) with black borders. Caudal fin orange-red to bright red and with dusky base.

Females and juveniles: body, cheeks, and operculum beige to yellow; dorsum with blue-green sheen; chest and belly white; flanks with 4-6 very faint and dusky vertical stripes (ESM Fig. S5d). Pectoral fins hyaline with yellow sheen; pelvic fins white. Dorsal fin dusky and with black lappets and maculated orange between branched rays; caudal fin dusky with yellow to orange extensions and dorsal part faintly maculated. Anal fin white and with yellow extensions and 3-5 orange spots that resemble egg spots.

\section{Colouration in alcohol}

Dorsum brown, ventral part of body silver-beige; body of dominant males uniformly dusky (Fig. 7). Flanks of some specimens with faint 4-6 vertical stripes. Pectoral fins hyaline; pelvic fins hyaline in females and juveniles, dark in dominant males. Dorsal, anal, and caudal fins dusky in all specimens; all with hyaline extensions and anal fin with 4-7 faint egg spots in dominant males. Nostril, interorbital, preopercular, and lachrymal stripes and a nape band faint and ill-defined.

\section{Ecology and distribution}

Endemic to the Lake Edward system, only known from Lake Edward. Gut short (111-155\% SL, $n=3$ ), diet insectivorous. We examined the guts of five specimens. Two were filled mostly with larvae of Chironomidae, Ephemeroptera, and Trichoptera, in addition to some Hydrachnidia and, in one of these guts, Ostracoda. Two guts were almost empty but contained some larvae of Ephemeroptera or Trichoptera, one further contained a specimen of Hydrachnidia, and the other a few skeletal elements of small fish. The last gut was empty.

\section{Differential diagnosis}

Haplochromis lobatus sp. nov. differs from all species of Haplochromis from the Lake Edward system by a combination of an elongated and slender snout, strongly pro- to isognathous jaws, deep lower jaw with blunt teeth, and lobed lips that are mostly enlarged medially. It can be confused with $\mathrm{H}$. labiatus as both have lobed lips, a small gape, a curved upper jaw with a relatively long premaxillary pedicel [82.4-116.3 (102.1) \% UJL], stout and unicuspid outer teeth that strongly decrease in size laterad, and a lower jaw set anteriorly with procumbently implanted outer teeth $\left(40-70^{\circ}\right.$ to vertical). It differs from this species by a straight to concave vs. straight to convex head, and an elongated and slender vs. blunt and more broad snout (Tables 1,ESM S4). Differs further in its trophic morphology: lower jaw slightly longer [31.2-40.7 (36.6) vs. 27.7-34.3 (31.0) \% HL] and more slender [48.5-70.5 (62.7) vs. 71.4-92.4 (80.3) \% LJL], jaws iso- to strongly prognathous vs. iso- to retrognathous, and anteriormost outer teeth in lower jaw more widely 
set (1-2 vs. $0-1$ outer tooth widths between adjacent teeth) and with longer major cusps.

Haplochromis lobatus resembles H. chilotes from Lake Victoria by its very slender and acute snout, lobed lips, and insectivorous diet. It differs by having: larger eyes [28.5-34.2 (31.3) vs. 21.8-28.6 (25.4) \% HL], a correlated shorter snout [26.9-32.9 (30.6) vs. 30.8-38.4 (34.0) \% HL], and iso- to strongly prognathous vs. isognathous jaws. It further differs in live colouration: flanks with faint vertical stripes vs. vertical and longitudinal stripes, flanks of dominant males uniformly beige to yellow vs. blueish with orange chest and greenish caudal peduncle, and anal fin of dominant males dusky to black with yellow to orange extensions vs. pale red in H. chilotes (Seehausen, 1996). Haplochromis lobatus resembles superficially $H$. paucidens from Lake Kivu by its lobed lips, but clearly differs by its acute vs. blunt snout and more slender lower jaw [48.5-70.5 (62.5) vs. 76.0-90.7 (80.2) \% LJL].

\section{Discussion}

Within most of the East African Great Lakes, a trophic group is often represented by many species of cichlids. This is, however, not the case for species with a lobed-lipped phenotype. Lake Tanganyika, for example, is inhabited by only one species with lobed lips (Kohda et al., 2008), Lake Victoria by one or two species (Seehausen, 1996), and Lake Malawi by only a handful of species (Snoeks, 2004; Konings, 2007), while each of these lakes harbours a flock of 250-1000 species (Salzburger and Meyer, 2004). In addition, Lake Kivu contains also one such species (Snoeks, 1994), but no lobed-lipped species is known from the basin of Lake Albert. The Lake Edward system is home to two species with lobed lips: H. labiatus and H. lobatus sp. nov. The latter was hitherto unknown to science. While both species appear to be relatively rare, $H$. labiatus seems more abundant than $H$. lobatus sp. nov., based on extensive sampling during three expeditions (2016-2018) (ESM Fig. S7).

Both lobed-lipped species from the Lake Edward system have a trophic morphology that resembles 'Paralabidochromis' sensu Greenwood (1980) with relatively short and stout oral jaws and few, straight, and stout outer teeth that are procumbently implanted in the anterior part of the lower jaw. Although, typically, species with a 'Paralabidochromis' morphology possess isognathous jaws, they are mostly prognathous in H. lobatus sp. nov. and mostly retrognathous in H. labiatus. Haplochromis labiatus further deviates from this morphology by a slightly shorter lower jaw [27.1-33.6 (31.0) vs. 30-49 (modal range 33-35) \% HL] and a straight to convex head vs. a straight to weakly concave head in 'Paralabidochromis'.

Within the Lake Victoria region, two other species are known to display lobed lips: $H$. paucidens from Lake Kivu and $H$. chilotes from Lake Victoria. Haplochromis labiatus resembles $H$. paucidens as both species have concave heads, relatively broad jaws that are iso- to retrognathous, and lips that are lobed uniformly over their whole lengths (Snoeks, 1994). The trophic morphology of $H$. lobatus sp. nov., although similar to that of $H$. labiatus, resembles more closely the habitus of $H$. chilotes from Lake Victoria. Both species have very slender jaws, and lobed lips in which the medial parts are enlarged, while the strongly prognathous jaws of $H$. lobatus sp. nov. are absent in H. chilotes (Greenwood, 1959; Seehausen, 1996). Differences in counts were absent between all lobed-lipped species. This is not surprising as counts show little value in distinguishing between species of Haplochromis (Snoeks, 1994; Barel et al., 1977).

Both H. labiatus and H. lobatus sp. nov. have slightly larger eyes than their resembling congeners (in \% HL): 31.0-36.9 (34.4) for H. labiatus vs. 27.1-35.8 (31.5) for H. paucidens, and 28.5-34.2 (31.3) for H. lobatus sp. nov. vs. 21.8-28.6 (25.4) for H. chilotes (Greenwood, 1959). Also, the oral mollusc shelling species of Haplochromis from Lake Edward have larger eyes than those from Lake Victoria (Vranken, unpublished data). Similar to these species (Witte et al., 2013), lobed-lipped species may have a visually-based hunting technique. The transparency of Lake
Edward was lower than that of Lake Victoria (Levring and Fish, 1956), prior to the latter's increased eutrophication (Seehausen et al., 1997). The larger eyes of the lobed-lipped species from Lake Edward may form an adaptation to low-light conditions. This may also explain the probable absence of lobed-lipped species from the much murkier Lake George.

The two lobed-lipped species from the Lake Edward system resemble each other in overall morphology and show relatively similar colour patterns. However, they differ in their trophic morphologies. The most distinct difference between $H$. lobatus sp. nov. and $H$. labiatus is in the anterior extension of the lower jaw. Haplochromis lobatus sp. nov. has iso- to strongly prognathous jaws, quite unlike the iso- to retrognathous jaws of $H$. labiatus. In our knowledge, a difference in the anterior extension of the lower jaw has not been recorded for other sympatric species of lobed-lipped cichlids (Snoeks, 2004; Konings, 2007). However, within specimens of $H$. chilotes from Lake Victoria, two morphotypes are recognised that differ in snout acuteness and lower jaw length, but both have isognathous jaws (Greenwood, 1959; Seehausen, 1996). Differences in the mouth type are present in two thick-lipped species of pupfishes from Laguna Chichancanab. Cyprinodon labiosus has a superior mouth, while C. suavium has a terminal mouth (Strecker, 2005), hence showing similarities to H. lobatus sp. nov. and H. labiatus, respectively. These pupfishes differ in food preferences; the species with a superior mouth feeds on amphipods, while the one with a terminal mouth on snails. Such differences in diet have not been observed in the lobedlipped cichlids from Lake Edward while they are present in lobed-lipped cichlids from other lakes that show no notable differences in the extensions or widths of their lower jaws. Therefore, lobed lips cannot be linked to a single ecological niche. Most lobed-lipped species of cichlids throughout Africa, and even the Neotropics, have either a mollusc crushing or insectivorous ecology. The hypertrophication of the lips seems to form an adaptation that is more strongly linked to a specific feeding behaviour. Most species of lobed-lipped cichlids are specialised in suction feeding in association with hard substrates (Colombo et al., 2013; Manousaki et al., 2013; Baumgarten et al., 2015).

Haplochromis labiatus and $H$. lobatus sp. nov. both have diets that consist mainly of larvae of Chironomidae, Ephemeroptera, and Trichoptera. A related species with lobed lips, $H$. chilotes from Lake Victoria, also has similar food preferences. This species is known to use its slender and elongated snout and lobed lips to reach into crevices in hard substrates or interstices between stones to suck out the insect larvae hiding inside (Baumgarten et al., 2015). The strikingly similar trophic morphology of $H$. lobatus sp. nov. presumably indicates that it has a similar feeding behaviour. The feeding behaviour of $H$. labiatus, however, has remained unknown (Trewavas, 1933), as has this behaviour of the morphologically-resembling species $H$. paucidens. In contrast to slender-jawed species, $H$. labiatus has broader jaws in combination with lobed lips which may form adaptations to suck insect larvae from flat surfaces, as might be present on the hardened-sediment that is often found on the lakebed of Lake Edward. Haplochromis labiatus may use its lips to seal off irregularities in hard substrates or in vegetation, where insect larvae may seek shelter. For example, mayfly larvae that make their burrows in dead stems and rhizomes of papyrus (Efitre et al., 2001). This presumed behaviour is supported by the abraded teeth of many specimens of $H$. labiatus, as the outer teeth can wear off because of the contact with such hard substrates. In addition to the difference in broadness of the jaw apparatus, the lobed-lipped species from the Lake Edward system display a strong difference in the anterior extension of their lower jaws. This may represent an additional divergence in feeding behaviour and microhabitat. The strongly prognathous lower jaw of $H$. lobatus sp. nov. may be specifically adapted to reach corners and gaps between horizontally and vertically-orientated surfaces, such as at the bases between thick stems of papyrus, while the retrognathous lower jaw of $H$. labiatus may be adaptive to feed from horizontally-orientated surfaces. Both lobed-lipped species from the Lake Edward system live sympatrically and presumably syntopically 
as they were often caught in the same nets (Fig. S7). While they also have similar diets, the interspecific differences in feeding apparatus may indicate a difference in feeding behaviour and/or microhabitat, as has already been observed for other species of Haplochromis (Goldschmidt et al., 1990). These differences may prevent them from entering in direct ecological competition with one another.

The evolution of the Lake Victoria region superflock (LVRS) has remained poorly understood (Bezault et al., 2011; Meier et al., 2017; Muschick et al., 2018). Species of Haplochromis can display fast morphological adaptations in changing environments (Elmer et al., 2010; van Rijssel and Witte, 2013). Furthermore, numerous examples of convergent evolution are known within East African cichlids (Muschick et al., 2012). Especially the LVRS has had a complex evolutionary history through changing hydrological connections resulting in subsequent colonisation events of Haplochromis of the different water bodies (Danley et al., 2012). Furthermore, morphological comparison has proven misleading in deducing evolutionary relationships (Greenwood, 1980; Hoogerhoud, 1984; van Oijen, 1996).

We recognise strong morphological resemblances between H. labiatus and H. lobatus sp. nov., two lobed-lipped species from Lake Edward. Only one measurement does not show any overlap between both species (lower jaw width), hereby illustrating that morphological differences may be small between distinct species of Haplochromis (Barel et al., 1977). The lobed-lipped species from Lake Edward may well be sister species that diverged in trophic morphology, hereby avoiding competition through niche differentiation (van Rijssel et al., 2018). Additionally, Meier et al. (2017) found some support for the monophyly of the Lake Victoria assemblage, which would imply a convergent evolution between $H$. chilotes and its congeners from Lakes Edward and Kivu. However, that study did not contain any lobed-lipped species, so we cannot exclude that the lobed-lipped species from the LVRS form a monophyletic lineage. Regardless of their evolutionary history, as the LVRS contains relatively few lobed-lipped species, these form a promising framework to test evolutionary scenarios.

\section{Acknowledgements}

This research was conducted within the framework of the BELSPO (Belgian Science Policy) funded BRAIN project "HIPE": Human impacts on ecosystem health and resources of Lake Edward. The fieldwork of M.V.S. was supported by the FWO (Research Foundation Flanders, V435116N) and the King Leopold III Fund for Nature Exploration and Conservation, Belgium. We thank E. Decru (RMCA), M. Mulongaibalu (Université Officielle de Bukavu, DRC), and L. Mwaiswa (Ugandan Fisheries Department) for their help in collecting specimens. We are grateful to M. Parrent (RMCA) for curatorial services.

\section{Appendix A. Supplementary data}

Supplementary data to this article can be found online at https://doi. org/10.1016/j.jglr.2019.05.005.

\section{References}

Arnegard, M.E., Snoeks, J., 2001. New three-spotted cichlid species with hypertrophied lips (Teleostei: Cichlidae) from the deep waters of Lake Malawii/Nyasa, Africa. Copeia 2001, 705-717.

Balole-Bwami Lubala, E., Mumbere, J.-C., Matunguru Masirika, J., Kujirakwinja, D., Shamavu, P., Muhind, E., Tchouamo, I.R., Baudouin, M., Micha, J.-C., 2018. Production et impacts de la pêche dans la partie congolaise du Lac Edouard. Tropicultura 36, 539-552.

Barel, C.D.N., 1983. Towards a constructional morphology of cichlid fishes (Teleostei, Perciformes). Neth. J. Zool. 33, 357-424.

Barel, C.D.N., Witte, F., van Oijen, M.J.P., 1976. The shape of the skeletal elements in the head of a generalized Haplochromis species: H. elegans Trewavas 1933 (Pisces, Cichlidae). Neth. J. Zool. 26, 163-265.

Barel, C.D.N., van Oijen, M.J.P., Witte, F., Witte-Maas, E.L.M., 1977. An introduction to the taxonomy and morphology of the haplochromine cichlidae from Lake Victoria. Neth. J. Zool. 27, 333-380.
Baumgarten, L., Machado-Schiaffino, G., Henning, F., Meyer, A., 2015. What big lips are good for: on the adaptive function of repeatedly evolved hypertrophied lips of cichlid fishes. Biol. J. Linn. Soc. 115, 448-455.

Bezault, E., Mwaiko, S., Seehausen, O., 2011. Population genomic tests of models of adaptive radiation in Lake Victoria region cichlid fish. Evolution 65, 3381-3397.

Boulenger, G.A., 1898. Report on the fishes recently obtained by Mr. J. E. S. Moore in Lake Tanganyika. Proc. Zool. Soc. London 494-497.

Boulenger, G.A., 1911. On a third collection of fishes made by Dr. E. Bayon in Uganda, 1909-1910. Ann. del Mus. Civ. di Stor. Nat. di Genova 5, 64-78.

Boulenger, G.A., 1914. Fam. Cichlidae, in: Wissenschaftliche Ergebnisse Der Deutschen Zentral-Africa-Expedition. 1907-1908 pp. 253-260.

Colombo, M., Diepeveen, E.T., Muschick, M., Santos, M.E., Indermaur, A., Boileau, N., Barluenga, M., Salzburger, W., 2013. The ecological and genetic basis of convergent thick-lipped phenotypes in cichlid fishes. Mol. Ecol. 22, 670-684.

Danley, P.D., Husemann, M., Ding, B., Dipietro, L.M., Beverly, E.J., Peppe, D.J., 2012. The impact of the geologic history and paleoclimate on the diversification of East African cichlids. Int. J. Evol. Biol. 2012, 20.

de Graaf, M., Dejen, E., Osse, J.W.M., Sibbing, F.A., 2008. Adaptive radiation of Lake Tana's (Ethiopia) Labeobarbus species flock (Pisces, Cyprinidae). Mar. Freshw. Res. 59, 391-407.

de Zeeuw, M.P., Mietes, M., Niemantsverdriet, P., ter Huurne, S., Witte, F., 2010. Seven new species of detritivorous and phytoplanktivorous haplochromines from Lake Victoria. Zool. Meded. Leiden 84, 201-250.

Dunn, I.G., 1989. Fisheries management study in the Queen Elizabeth National Park. Mission report for EEC Project No. 4100.037.42.44. Agriconsulting, Rome.

Efitre, J., Chapman, L.J., Makanga, B., 2001. The inshore benthic macroinvertebrates of Lake Nabugabo, Uganda: seasonal and spatial patterns. Afr. Zool. 36, 205-216.

Elmer, K.R., Lehtonen, T.K., Kautt, A.F., Harrod, C., Meyer, A., 2010. Rapid sympatric ecolog ical differentiation of crater lake cichlid fishes within historic times. BMC Biol. 8, 60 .

Fryer, G., Iles, T.D., 1972. The cichlid fishes of the Great Lakes of Africa. Their biology and evolution. Copeia 1973, 187.

Goldschmidt, T., Witte, F., de Visser, J., 1990. Ecological segregation in zooplanktivorous haplochromine species (Pisces: Cichlidae) from Lake Victoria. Oikos 58, 343-355.

Golubtsov, A.S., Cherenkov, S.E., Tefera, F., 2012. High morphological diversity of the genus Garra in the Sore River (the White Nile Basin, Ethiopia): one more cyprinid species flock? J. Ichthyol. 52, 817-820.

Greenwood, P.H., 1956. The monotypic genera of cichlid fishes in Lake Victoria. B. Brit. Mus. Nat. His. Zool. 3, 295-333.

Greenwood, P.H., 1959. A revision of the Lake Victoria Haplochromis species (Pisces, Cichlidae), part III. B. Brit. Mus. Nat. His. Zool. 5, 179-218.

Greenwood, P.H., 1973. A revision of the Haplochromis and related species (Pisces: Cichlidae) from Lake George, Uganda. B. Brit. Mus. Nat. His. Zool. 25, 139-242.

Greenwood, P.H., 1979. Towards a phyletic classification of the "genus" Haplochromis (Pisces, Cichlidae) and related taxa. Part I. B. Brit. Mus. Nat. His. Zool. 35, 265-322.

Greenwood, P.H., 1980. Towards a phyletic classification of the "genus" Haplochromis (Pisces, Cichlidae) and related taxa. Part II: the species from lakes Victoria, Nabugabo, Edward, George and Kivu. B. Brit. Mus. Nat. His. Zool. 39, 1-101.

Greenwood, P.H., 1991. Speciation. In: Keenleyside, M.H. (Ed.), Cichlid Fishes: Behaviour, Ecology and Evolution, Fish \& Fisheries Series. Springer, pp. 86-102.

Günther, A., 1864. On some new species of central-American fishes. Proc. Zool. Soc. London 1, 23-27.

Hammer, Ø., Harper, D.A.T.a.T., Ryan, P.D., 2001. PAST: paleontological statistics software package for education and data analysis. Palaeontol. Electron. 4, 1-9.

Hecky, R.E., Degens, E.T., 1973. Late Pleistocene-Holocene Chemical Stratigraphy and Paleolimnology of the Rift Valley Lakes of Central Africa. Woods Hole Oceanographic Institution, Massachusetts https://hdl.handle.net/1912/4362.

Hilgendorf, F.M., 1888. Fische aus dem Victoria-Nyanza (Ukerewe-See), gesammelt von dem verstorbenen Dr. G. A. Fischer. Sitzungsber. Ges. Naturf. Freunde Berlin 75-79.

Hoogerhoud, R.J.C., 1984. A taxonomic reconsideration of the haplochromine genera Gaurochromis Greenwood, 1980 and Labrochromis Regan, 1920 (Pisces, Cichlidae). Neth. J. Zool. 34, 539-565.

Humphries, J.M., Miller, R.R., 1981. A remarkable species flock of pupfishes, genus Cyprinodon, from Yucatán, Mexico. Copeia 1, 52-64.

Klingenberg, C.P., 2011. MorphoJ: an integrated software package for geometric morphometrics. Mol. Ecol. Sources 11, 353-357.

Kohda, M., Shibata, J.Y., Awata, S., Gomagano, D., Takeyama, T., Hori, M., Heg, D., 2008 Niche differentiation depends on body size in a cichlid fish: a model system of a community structured according to size regularities. J. Anim. Ecol. 77, 859-868.

Konings, A., 2007. Malawi Cichlids in their Natural Habitat. 4th ed. Cichlid Press.

Konings, A., 2014. Tropheus in Their Natural Habitat. Cichlid Press, El Paso.

Levring, T., Fish, G.R., 1956. The penetration of light in some tropical East African waters. Oikos 7, 98-109.

Losos, J.B., 2011. Convergence, adaptation, and constraint. Evolution 65, 1827-1840.

Lucena, C.A.S., Kullander, S.O., 1992. The Crenicichla (Teleostei: Cichlidae) species of the Uruguai River drainage in Brazil. Ichthyol. Explor. Fres. 3, 97-160.

Machado-Schiaffino, G., Henning, F., Meyer, A., 2014. Species-specific differences in adaptive phenotypic plasticity in an ecologically relevant trophic trait: hypertrophic lips in midas cichlid fishes. Evolution 68, 2086-2091.

Manousaki, T., Hull, P.M., Kusche, H., Machado-Schiaffino, G., Franchini, P., Harrod, C., Elmer, K.R., Meyer, A., 2013. Parsing parallel evolution: ecological divergence and differential gene expression in the adaptive radiations of thick-lipped Midas cichlid fishes from Nicaragua. Mol. Ecol. 22, 650-669.

Meier, J.I., Marques, D.A., Mwaiko, S., Wagner, C.E., Excoffier, L., Seehausen, O., 2017. Ancient hybridization fuels rapid cichlid fish adaptive radiations. Nat. Commun. 8, 11.

Muschick, M., Indermaur, A., Salzburger, W., 2012. Convergent evolution within an adaptive radiation of cichlid fishes. Curr. Biol. 22, 2362-2368. 
Muschick, M., Russell, J.M., Jemmi, E Walker, J., Stewart, K.M., Murray, A.M., Dubois, N, Stager, J.C., Johnson, T.C., Seehausen, O., 2018. Arrival order and release from competition does not explain why haplochromine cichlids radiated in Lake Victoria. P. Roy. Soc. B-Biol. Sci. 285

Oliver, M.K., Arnegard, M.E., 2010. A new genus for Melanochromis labrosus, a problematic Lake Malawi cichlid with hypertrophied lips (Teleostei: Cichlidae). Ichthyol. Explor. Fres. 21, 209-232.

Pfaender, J., Hadiaty, R.K., Schliewen, U.K., Herder, F., 2016. Rugged adaptive landscapes shape a complex, sympatric radiation. P. Roy. Soc. B-Biol. Sci. 283.

Rasband, W.S., 2018. ImageJ, Version 1.52a.

Rice, W.R., 1989. Analyzing tables of statistical tests. Evolution 43, 223-225.

Rohlf, F.J., 2017a. tpsDig, digitize landmarks and oulines, (version 2.31).

Rohlf, F.J., 2017b. tps-Relw, relative warps analysis, (version 1.69).

Rüber, L., Adams, D.C., 2001. Evolutionary convergence of body shape and trophic morphology in cichlids from Lake Tanganyika. J. Evol. Biol. 14, 325-332.

Rundle, H.D., Nagel, L., Boughman, J.W., Schluter, D., 2000. Natural selection and paralle speciation in sympatric sticklebacks. Science 287, 306-308.

Rüppell, E., 1835. Neuer Nachtrag von Beschreibungen und Abbildungen neuer Fische, im Nil entdeckt. Museum Senckenbergianum: Abhandlungen aus dem Gebiete der beschreibenden Naturgeschichte, von Mitgliedern der Senckenbergischen Naturforschenden Gesellschaft in Frankfurt am Main.

Salzburger, W., 2018. Understanding explosive diversification through cichlid fish genomics. Nat. Rev. Genet. 19, 705-717.

Salzburger, W., Meyer, A., 2004. The species flocks of East African cichlid fishes: recent advances in molecular phylogenetics and population genetics. Naturwissenschaften 91 277-290.

Salzburger, W., Mack, T., Verheyen, E., Meyer, A., 2005. Out of Tanganyika: genesis, explosive speciation, key-innovations and phylogeography of the haplochromine cichlid fishes. BMC Evol. Biol. 5.

Santos, M.E., Salzburger, W., 2012. How cichlids diversify. Science 338, 619-621.

Seehausen, O., 1996. Lake Victoria Rock Cichlids: Taxonomy, Ecology, and Distribution. Verduyn Cichlids.

Seehausen, O., 2015. Process and pattern in cichlid radiations - inferences for understanding unusually high rates of evolutionary diversification. New Phytol. 207, 304-312.

Seehausen, O., van Alphen, J.J.M., Witte, F., 1997. Cichlid fish diversity threatened by eutrophication that curbs sexual selection. Science 277, 1808-1811.

Snoeks, J., 1994. The haplochromine fishes (Teleostei, Cichlidae) of Lake Kivu, East Africa: a taxonomic revision with notes on their ecology. Royal Museum for Central Africa, Tervuren, Belgium.
Snoeks, J., 2004. The Cichlid Diversity of Lake Malawi/Nyasa/Niassa: Identification, Distribution and Taxonomy. Cichlid Press. Cichlid Press.

Snoeks, J., Harrison, I.J., Stiassny, M.L.J., 2011. The status and distribution of freshwater fishes. In: Darwall, W.R.T., Smith, K.G., Allen, D.J. (Eds.), The Diversity of Life in African Freshwaters: Under Water, under Threat. An Analysis of the Status and Distribution of Freshwater Species throughout Mainland Africa. Cambridge, UK, pp. 42-91.

Strecker, U., 2005. Description of a new species from Laguna Chichancanab, Yucatan, Mexico: Cyprinodon suavium (Pisces: Cyprinodontidae). Hydrobiologia 541, 107-115.

Trewavas, E., 1933. Scientific results of the Cambridge expedition to the East African lakes, 1930-1. The cichlid fishes. J. Linn. Soc. London, Zool. 38, 309-341.

Trewavas, E., 1935. A synopsis of the cichlid fishes of Lake Nyasa. Ann. Mag. Nat. Hist. 10, 65-118.

van Oijen, M.J.P., 1996. The generic classification of the haplochromine cichlids of Lake Victoria, East Africa. Zool. Verh. 302, 57-110.

van Rijssel, J.C., Witte, F., 2013. Adaptive responses in resurgent Lake Victoria cichlids over the past 30 years. Evol. Ecol. 27, 253-267.

van Rijssel, J.C., Moser, F.N., Frei, D., Seehausen, O., 2018. Prevalence of disruptive selection predicts extent of species differentiation in Lake Victoria cichlids. P. Roy. Soc. B-Biol. Sci. 285.

Van Steenberge, M., Vanhove, M.P.M., Breman, F.C., Snoeks, J., 2013. Complex geographical variation patterns in Tropheus duboisi Marlier, 1959 (Perciformes, Cichlidae) from Lake Tanganyika. Hydrobiologia 748, 39-60.

Verheyen, E., Salzburger, W., Snoeks, J., Meyer, A., 2003. Origin of the superflock of cichlid fishes from Lake Victoria. East Africa. Science 300, 325-329.

Vranken, N., Van Steenberge, M., Snoeks, J., 2019. Grasping ecological opportunities: not one but five paedophagous species of Haplochromis (Teleostei: Cichlidae) in the Lake Edward system. Hydrobiologia 832, 105-134.

Witte, F., van Oijen, M.J.P., 1990. Taxonomy, ecology and fishery of Lake Victoria haplochromine trophic groups. Zool. Verh. 262, 1-47.

Witte, F., Witte-Maas, E.L.M., 1981. Haplochromine cleaner fishes: a taxonomic and ecomorphological description of two new species. Neth. J. Zool. 31, 203-231.

Witte, F., Seehausen, O., Wanink, J.H., Kishe-Machumu, M.A., Rensing, M., Goldschmidt, T., 2013. Cichlid species diversity in naturally and anthropogenically turbid habitats of Lake Victoria, East Africa. Aquat. Sci. 75, 169-183.

Zelditch, M.L., Swiderski, D.L., Sheets, H.D., Fink, W.L., 2004. Geometric Morphometrics for Biologists: A Primer. Elsevier Academic Press, London. 